\title{
Herpes Zoster: Description of the Associated Burden and Its Preventive Strategies
}

\author{
Pierre-Olivier Lang \\ Department of Internal Medicine, Rehabilitation and Geriatrics, Hospital of Trois-Chêne \\ Chemin du Pont-Bochet, 3. CH-1226 Thônex-Geneva, Switzerland \\ Tel: 41-22-305-6111 E-mail: pierre.o.lang@hcuge.ch
}

Received: November 24, 2011

Accepted: December 9, 2011

Published: March 1, 2012

doi:10.5539/res.v4n1p107

URL: http://dx.doi.org/10.5539/res.v4n1p107

\begin{abstract}
The burden of illness and healthcare resource utilisation associated with herpes zoster is substantial, causing severe loss of quality of life (QoL). Herpes zoster incidence varies from 1.5 to 5.0/ 1,000 person-years in adults of all ages, and reaches 10 cases/ 1,000 person-years in individuals aged $\geq 60$. The most frequent and debilitating complication is post-herpetic neuralgia (PHN). In the absence of antiviral therapy, up to $45 \%$ of $\geq 60$ year-olds experience pain which persists for 6 months to a year. The importance of preventive strategies for PHN is becoming widely recognised. Systematic reviews confirm the short-term benefits gained from antiviral drugs, but they do not reduce the incidence of PHN. When, complementary analgesic drugs are often required, prescribing advised medications in old, frail, co-morbid and poly-medicated patients must be carefully considered. Consequently, the first HZ vaccine with proven efficacy thus promotes healthy ageing and improved quality of life.
\end{abstract}

Keywords: Burden of illness, Herpes zoster, Post-herpetic neuralgia, Herpes zoster vaccine

\section{Introduction}

Reactivation of endogenous latent varicella-zoster virus (VZV) infection within the sensory ganglia results in Herpes zoster (HZ) or "shingles". Epidemiological studies estimate the incidence of HZ in the general population to be between 3 and 4 per 1,000 persons (Brisson M 2003; Edmunds WJ 2001; Insinga RP 2005; Opselten W 2002; Chidiac C 2001). However the risk of developing HZ increases markedly with age; the sharpest increase occurs between 50 and 60 years of age and continues on an upward trend, with HZ incidence of more than 10 per 1,000 persons reported for ages 60 or older (Hope-Simpson RE 1975; Thomas SL 2004). The age-related increase in $\mathrm{HZ}$ incidence has been suggested to be due to the impairment of immune responses incurred by ageing, diseases, and drug-related decline in cellular immunity (Thomas SL 2004). Shingles, usually characterised by a unilateral blistering cutaneous eruption with a dermatomal distribution, is also accompanied by severe pain. In some people, pain does not subside after healing but persists for months to years. This prolonged $\mathrm{HZ}$ associated pain, usually defined as a pain persisting for more than one month after the rash has healed, is known as post-herpetic neuralgia (PHN) and is the most common complication of HZ reactiviations (Wareham DW 2007).

Between 13 and $26 \%$ of patients with HZ develop PHN, and this increases to $50 \%$ in those aged 70 years or above (Scott FT 2006). The pain can be debilitating, exacerbated by the slightest touch, and can have a serious impact on quality of life (QoL), involving loss of employment, depression, and social isolation (Wareham DW 2007; Chidiac C 2001; Stein AN 2008). Several epidemiological reports have highlighted the substantial global burden associated with $\mathrm{HZ}$ and PHN, describing problems and difficulties in the personal, social and economic domains (Scott FT 2006; Stein AN 2008; Edmunds WJ 2001; Chidiac C 2001; Lang PO 2007).

In taking a preventive approach to the burden associated with $\mathrm{HZ}$, the identification of those patients at risk of developing PHN is crucial, as they stand to gain most from treatment. The following parameters have been suggested and evaluated as risk factors for predicting PHN: older age ( $>50$ years); female gender; presence of severe pain at presentation; disseminated rash; and polymerase chain reaction-detectable VZV viremia (Jung BF 
2004). This list is unlikely to be exhaustive. Several clinical trials have shown current antiviral drug treatments do not completely alleviate acute pain, and fail to prevent or manage PHN (Wood MJ 1996; Jackson JL 1997; Beutner KR 1995; Tyring S 1995; Wood MJ 1994). Consequently, complementary analgesic drugs are often required. However, prescription of advised medications in old, frail, co-morbid and poly-medicated patients have to be carefully considered as their use may be contraindicated (Lang PO 2009, 2010). In the present paper we provide an overview of the effectiveness of antiviral therapy in preventing $\mathrm{HZ}$ sequelae and the associated patient burden, with the aim of promoting $\mathrm{HZ}$ vaccination and its benefits in the older adult population.

\section{Herpes Zoster Burden of Illness}

The burden of illness includes both the impact on the well-being of the affected person, and the economic and social costs of managing the disease.(McGuire $T$ 2002) Health problems as well as the economic burden associated with HZ and its sequelae have previously been described (Scott FT 2006; Edmunds WJ 2001) (Stein AN 2008), (Lang PO 2007). In both community-dwelling adults of all ages, and in a hospital setting, the burden associated with $\mathrm{HZ}$ and its sequelae is substantial.

In the largest prospective observational study of $\mathrm{HZ}$ in community-dwelling patients, Chidiac et al supplied an objective measurement of the impact of $\mathrm{HZ}$ and PHN on QoL (Chidiac C 2001). 8,103 patients with acute HZ and 935 with PHN were seen over one year by 5,000 general practitioners (GPs) and dermatologists. Patients enrolled in the study were classified into 3 groups according to the reason for their initial visit to their health practitioner: (i) acute HZ; (ii) PHN, defined as the persistence of pain after healing of skin lesion; and (iii) other visceral and neurological complications. Each patient completed a questionnaire at the physician's office, designed to evaluate perceived pain and QoL with use of the standard Medical Outcome Study Short Form 36 (MOS SF-36). The main results are presented in table 1. Pain-related disruption of life activities during the week prior to consulting the physician was most severe for the patients experiencing PHN. The 7,595 QoL questionnaires completed showed that HZ had an adverse impact in all MOS SF-36 dimensions, in comparison to questionnaires completed by a French control reference population, matched for age and sex. The lowest values scores were seen in the PHN group. In particular, scores for physical functioning and emotional responses showed substantially larger decreases in the PHN group than in the other patient groups. Evidence of the effect on QoL in the PHN group was also shown by the high rate of use of alternative medical approaches; among PHN patients, $18 \%$ used acupuncture, homeopathy or auriculotherapy. This finding emphasizes the significant distress experienced due to HZ-related pain.

In Australia, using retrospective data (1998-2005) from emergency department and hospital records, Stein et al evaluated the health care resource utilization associated with HZ in individuals aged 50 years and above (Stein AN 2008). Hospitalisation rates increased markedly with age. The annual rate of hospitalisations in subjects aged 50 years or over was $28 / 100,000$ for those with a principal diagnosis of $\mathrm{HZ}$, and 39/100,000 for those with both $\mathrm{HZ}$ and other diagnoses. Most of hospitalizations were coded as $\mathrm{HZ}$ without complications (39\%) or HZ with PHN (35\%). Average length of stay was 6.8 days (6.0 for HZ without complications, and extended to more than 14 days for $\mathrm{HZ}$ encephalitis). For patients 50 years or older, who were hospitalised with non-principal diagnosis of HZ, the average length of stay was 15.5 days. At least part of the extended hospital stay was due to the principal reason for hospitalisation. The duration of stay attributable to HZ was estimated as 6.1 additional hospital days. The rate of total emergency visits increased with age. Amongst HZ cases, 38.2/100,000 persons were aged 50 or over. Furthermore, the proportion resulting in hospital admissions increased from $6 \%$ at ages $50-59$ to $33 \%$ in those aged 80 years and older.

A retrospective observational and hospital setting study conducted by Lang et al give similar results in oldest old

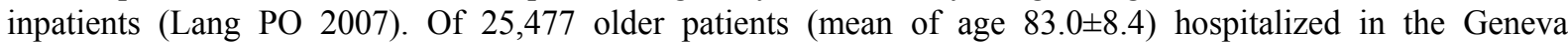
University Geriatrics Department between 1996 and 2003, 112 patients (mean age 85.5 \pm 8.0 ) were identified with $\mathrm{HZ}, 25 \%$ were older than 90 and $5 \%$ were over 100 years of age. Women represented $67 \%$ of the geriatric hospitalized patients and $75 \%$ of the $\mathrm{HZ}$ patients. The incidence rate was 4.88 per 1,000 admissions for women and 3.01 for men, with an incidence rate ratio of 1.61 (95\% confidence interval $-\mathrm{CI}: 1.02-2.63 ; p=0.03)$ for women compared to men. PHN (more than 3 months after the eruption) was the reason for hospitalization in $12 \%$ of the patients with HZ; an acute rash was present in 55\%. Symptoms of HZ appeared during the hospital stay in $33 \%$ of the patients. Pain at the acute eruptive phase was reported by $92 \%$ of the patients $(6.3 \pm 2.0$ on a 10 point visual analogical scale). The global functional assessment, according to the Functional Independence Measure (FIM)(Granger CV 1993) at the acute phase and two weeks later, demonstrated the functional burden associated with $\mathrm{HZ}$ disease. 
In a prospective study conducted in 96 community-dwelling patients with 8 months follow-up, Scott et al confirmed the HZ-associated health and medical burden and, in addition, described the economic and social burden (Scott FT 2006). Hospitalisations, severe pain and residual neurological deficit were more likely to occur in older patients, although two thirds of HZ cases occurred in those under 65 years. Severity was lower in this age group but the costs to society tended to be higher due to absence from work. Health economic trials estimate that shingles and PHN cost the United Kingdom up to 108 million Euro a year (Scott FT 2006; Edmunds WJ 2001). The main medical costs (including drugs, visits to the GPs, and hospital admissions) are estimated between 82 Euro et 220 Euro for each episode of HZ and 860 Euro for each episode of PHN (Edmunds WJ 2001). In patients aged under 65 , acute $\mathrm{HZ}$ is estimated to cost 585 Euro per episode, including costs resulting from lost productivity (Scott FT 2006).

\section{Preventive Approach to Herpes Zoster and the Consequent Burden Of Illness}

Prevention of HZ burden of disease involves either treatment of acute zoster or the use of a vaccine to decrease the incidence of acute zoster and its complications, PHN being the most challenging and debilitating of its potential sequelae. Another approach to prevent PHN involves very early treatment of acute zoster with preventive pain medications. Support for this approach comes from a double blind trial where 72 patients aged 60 or over with $\mathrm{HZ}$ were randomised to either placebo or amitriptyline $25 \mathrm{mg}$ daily for 90 days (Bowsher D 1997). Treatment was started within 48 hours of the onset of rash. Antiviral agents were administered according to the preference of the primary physician. At six weeks the pain prevalence (considered as the primary outcome measure) was reduced by about $50 \%$ in the group assigned to the amitriptyline antidepressant treatment. However, orthostatic hypotension and anticholinergic side-effects limit the utility of tricyclic drugs, particularly in old adults.

In an animal study, early treatment with gabapentine produced marked reduction in the incidence of PHN (Kuraishi Y 2004). There are as yet no clinical data for humans evaluating this treatment in a preventive approach for PHN. Epidural injection therapy with steroids and local anesthetics is commonly used in many countries to treat HZ but appears to have no benefit for preventing PHN (van Wijck AJ 2006).

\subsection{Preventive approach by antiviral therapy}

Antiviral therapy (Acyclovir, Valaciclovir, Famciclovir), started within 72 hours of rash onset, decreases the severity and duration of acute pain. Several meta-analyses and many (but not all) randomized controlled trials have demonstrated that prompt use of antiviral therapy for $\mathrm{HZ}$ reduces duration of pain by approximately $50 \%$, and may reduce the overall incidence of PHN and reduce the duration or incidence of prolonged pain significantly (Table 2) (Johnson RW 2003; Dworkin RH 2007).

Acyclovir (ACV) has an excellent safety profile but is only moderately active against VZV in vitro. Although oral ACV has been the mainstay of HZ treatment, its poor bioavailability and requirement for 5 daily doses has prompted the design of newer antiviral agents (Jackson JL 1997). Despite these limitations, ACV used within 48 to 72 hours of rash onset has demonstrated clinical benefit: (i) in one meta-analysis of four placebo controlled-trials, ACV accelerated resolution of the acute pain, with greatest effect in those over 50 years old (Wood MJ 1996); (ii) in a second meta-analysis, treatment with ACV significantly reduced the incidence of PHN at 6 months by $46 \%$ (Jackson JL 1997). However it is important to note that in the various antiviral trials, about $20 \%$ of patients over 50 continued to have pain for 6 months after their rash appeared, despite treatment beginning within 72 hours of rash onset (Dworkin RH 2007).

Corticosteroids have been assessed by Whitley et al in combination with ACV in a randomized, placebo controlled trial in 201 immunocompetent adults over the age of 50 years, in an attempt to improve QoL, time to skin healing, and the incidence of PHN (Whitley RJ 1996). The treated group had significantly accelerated times to total crusting and total healing compared to the control group. Patients receiving combination therapy were also twice as likely to resume uninterrupted sleep and three times more likely to regain $100 \%$ of prior activity and to discontinue analgesics, compared to those receiving placebo. Compared to ACV alone, combination with prednisone was associated with faster resolution of acute pain and earlier discontinuation of analgesic medications. However, individuals with contraindications to the use of corticosteroids were excluded form these studies, and several serious adverse effects of corticosteroids were reported.

Valaciclovir (VCV) is a well absorbed from the gastrointestinal tract and rapidly converted to ACV in vivo, thereby providing a three- to five-fold increase in ACV bioavailability (Beutner KR 1995). It efficacy was demonstrated by Beutner et al in a randomized, double-blind study in 1,141 immunocompetent adults older than 50 years with HZ (Beutner KR 1995). Efficacy and safety were compared to ACV. In an intent to treat analysis, $\mathrm{VCV}$ therapy compared to ACV for 7 to 14 days significantly accelerated the resolution of $\mathrm{HZ}$ associated acute 
pain, reduced the duration of PHN, and decreased the proportion of patients with pain persisting more than 6 months (19vs 26\%), with similar incidence of adverse events in the 2 groups.

Famciclovir (FCV) is also well absorbed from the gastrointestinal tract and rapidly converted in the intestinal wall and liver to the active compound penciclovir that has broad activity against VZV(Tyring S 1995). Tyring et $a l$, in a double-blind randomized controlled trial, evaluated oral FCV in 419 immunocompetent adults (mean age 50 years) with uncomplicated HZ (Tyring S 1995). FCV was well tolerated and accelerated lesion healing compared to placebo. FCV recipients had a two-fold faster resolution of PHN than those in the control group. The median duration of PHN was reduced by two months with FCV therapy.

Finally, treatment of $\mathrm{HZ}$ is chiefly directed towards minimizing the risk of prolonged pain. Initiated within the first 72 hours of the rash, all three antiviral drugs have demonstrated efficacy and are associated with more rapid resolution of acute neuritis; however, their effect in the prevention of PHN is not significant as demonstrated by a recent Cochrane Database Systematic review (Li Q 2009). The clinical utility of initiating antiviral drug beyond the first 72 hours after the onset of the rash has not been established. However, treatment could be initiated in case of new lesions appearing at that time. Guidelines for antiviral drug prescription in old adults are presented in table 2 .

\subsection{Immunological preventive approach}

Age-related reduction in cell-mediated immunity to VZV is the main cause of VZV reactivation in the immunosuppressed and the elderly population (Kimberlin DW 2007). However, subclinical VZV infections occurring periodically increase the cell-mediated immune responses which limit the spread of virus.(Levin MJ 1996) A similar boost in VZV cell-mediated immunity has been observed in immunocompromised hosts who experience asymptomatic VZV viremia (Kimberlin DW 2007).

Two clinical trials in older patients showed that immunity to VZV is boosted after immunization with live attenuated varicella vaccine (Gilden DH 2005). In one study, vaccine was administered to 202 healthy adults aged 55 to 87 years old, who demonstrated an enhanced VZV cell-mediated immune response. The frequency of VZV-specific proliferating T-cells was increased from 1 in 68,000 to 1 in 40,000, which is similar to the ratio seen in 35 to 40 year olds (Gilden DH 2005). In a large randomized, double-blind, placebo-controlled study, involving 38,546 adults aged 60 or more, Oxman et al. demonstrated that VZV-specific cell-mediated immunity was boosted by vaccination with live attenuated Oka/Merk vaccine. The HZ vaccine contains 18,700 to 60,000 plaque-forming units of virus, considerably more than the 1,350 plaque-forming units found in the Oka/Merk VZV vaccine for prevention of varicella. One of the main end points, over three years of surveillance, was the burden of illness, defined as a composite of the incidence, severity, and duration of pain and discomfort caused by HZ (Oxman MN 2008, 2005). The enhanced immunity was associated with a significant reduction both in the burden of illness $(61 \%, 95 \%$ CI: 51 - 69) and the incidence of PHN (66\%, 95\% CI: 47 - 79). The incidence of $\mathrm{HZ}$ was also significantly reduced by $51 \%(95 \%$ CI: $44-57)$ in the vaccine group. HZ vaccine was well tolerated, and injection site reactions were generally mild. HZ vaccine neither caused nor induced HZ. This study by Oxman et al. demonstrates the effectiveness of specific immune reactivation by Oka/Merk vaccine on $\mathrm{HZ}$ incidence and acute zoster related-pain, and reduced duration and intensity of PHN in HZ reactivation. Availability of vaccine for prevention of $\mathrm{HZ}$ (Oka/Merk vaccine - Zostavax ${ }^{\circledR}$ ) constitutes an important therapeutic advance and represents a milestone in improving the health of old and ageing adults. With high uptake, this vaccine has the potential to prevent an enormous burden of disease resulting from $\mathrm{HZ}$ and its primary complication, PHN. Although cost-effective analyses of immunization for HZ are currently hampered by the unknown duration of vaccine protection (Hornberger J 2006; Lang PO 2011), the Advisory Committee on Immunization Practices (ACIP) recommends routine $\mathrm{HZ}$ vaccination for prevention of both VZV reactivation and post-herpetic neuralgia in healthy adults aged 60 years-old and over. Moreover, ACIP recommends that the vaccine should be offered to patients at the first available clinical encounter with their health provider. This vaccine is not advised for use in pregnant women or in individuals with primary or acquired immunodeficiencies, or patients on immunosuppressive therapies (Centers for Disease Control and Prevention (CDC) 2008).

However, soon after its availability in the United States, coverage among adults recommended to receive the HZ vaccine was low, only 1.9\% (95\% IC: 1.3 - 2.8), based on the 2007 National Immunization Survey-Adult, in individuals over 60 year of age (Lu P 2009). A total of $72 \%$ of respondents were unaware of the HZ vaccine but $78 \%$ stated they would accept vaccination if their doctor recommend it. Key reasons for not accepting HZ vaccine included 'vaccination not needed' (35\%), 'not at risk' (13\%), and 'don't trust in doctors or medicine' $(10 \%)$. In their conclusion, the authors proposed strategies to improve vaccination rates. These included linking delivery of $\mathrm{HZ}$ vaccine to delivery of other indicated adult vaccines (e.g. influenza) and preventive-health 
interventions, so that patients will automatically be offered indicated vaccines, and establishing practice-based audits or physician-reminder systems. Residents of nursing homes and long-term-care facilities who are 60 years old or over also should be included in routine vaccination activities. When administering zoster vaccine, health care providers should review the patient's vaccination status for all indicated vaccines. Additionally, official recommendations should be widely disseminated to physicians (Centers for Disease Control and Prevention (CDC) 2008; Lu P 2009; Lang PO 2011).

\section{Conclusion}

Acute $\mathrm{HZ}$ and its sequelae are an economic burden to the health care service, society and the individual, causing severe loss of QoL in a subset of those affected. Current therapeutic options do not alleviate completely the acute pain and fail to prevent or manage PHN. HZ and PHN will remain important clinical problems for the foreseeable future. Several therapeutic recommendations for herpes zoster related-pain have been formulated recently, but in the context of old patients' frailty, co-morbidities and polypharmacy, the recommended medications must be carefully considered. In addition, Zostavax ${ }^{\circledR}$ is presented as a therapeutic advancement in the preventive approach of herpes zoster in this population.

\section{References}

Beutner, K. R., Friedman, D. J., Forszpaniak, C., Andersen, P. L. \& Wood, M. J. (1995). Valaciclovir compared with acyclovir for improved therapy for herpes zoster in immunocompetent adults. Antimicrob Agents Chemother, 39, 1546-1553.

Bowsher, D. (1997). The effects of pre-emptive treatment of postherpetic neuralgia with amitriptyline: a randomized, double-blind, placebo-controlled trial. J Pain Symptom Manage, 13, 327-331. http://dx.doi.org/10.1 016/S0885-3924(97)00077-8

Brisson, M. \& Edmunds, W. J. (2003). Epidemiology of varicella-zoster in England and Wales. J Med Virol, 70 (Suppl 1):S9-14. http://dx.doi.org/10.1002/jmv.10313

Centers for Disease Control and Prevention (CDC). (2000). Adult immunization programs in nontraditional settings: quality standards and guidance for program evaluation - a report of the National Vaccine Advisory Committee. MMWR, 49(RR-1).

Centers for Disease Control and Prevention (CDC). (2008). Prevention of Herpes zoster recommendations of the advisory committee on immunization practices (ACIP). $M M W R, 57,1-30$

Chidiac, C., Buxelles, J., Daures, J. P., Hoang-Xuan, T., Morel, P. and Leplege, A. et al. (2001). Characteristics of patients with herpes zoster on presentation to practitioners. France. Clin Infect Dis, 33, 62-69. http://dx.doi.org $/ 10.1086 / 320884$

Dworkin, R. H., Johnson, R. W., Breuer, J., Gnann, J. W., Levin, M. J. \& Backonja, M. (2007). Recommendations for the management of herpes zoster. Clin Infect Dis, 44:S1-26. http://dx.doi.org/10.1086/510 206

Edmunds, W. J., Brisson, M. \& Rose, J. D. (2001). The epidemiology of herpes zoster and potential cost-effectiveness of vaccination in England and Wales. Vaccine, 19, 3076-3090. http://dx.doi.org/10.1016/S02 64-410X(01)00044-5

Gilden, D. H. (2005). Varicella-zoster virus vaccine - grown ups- need it, too. $N$ Eng J Med, 352, 2344-2346. http://dx.doi.org/10.1056/NEJMe058090

Granger, C. V., Hamilton, B. B., Linacre, J. M., Heinemann, A. W. \& Wright, B. D. (1993). Performance profiles of the functional independence measure. Am J Phys Med Rehabil, 72, 84-89 http://dx.doi.org/10.1097/00 002060-199304000-00005

Hope-Simpson, R. E. (1975). Postherpetic neuralgia. J R Coll Gen Pract, 25, 571-575.

Hornberger, J. \& Robertus, K. (2006). Cost-effectiveness of a vaccine to prevent herpes zoster and postherpetic neuralgia in older adults. Ann Intern Med, 145, 317-325.

Insinga, R. P., Itzler, R. F., Pellissier, J. M., Saddier, P. \& Nikas, A. A. (2005). The incidence of herpes zoster in a United States administrative database. J Gen Intern Med, 20, 748-753. http://dx.doi.org/10.1111/j.1525-1497.

2005.0150.x

Jackson, J. L., Gibbons, R, Meyer, G. \& Inouye, L. (1997). The effect of treating herpes zoster with oral acyclovir in preventing postherpetic neuralgia. A meta-analysis. Arch Intern Med, 157, 909-912. http://dx.doi.org /10.1001/archinte.157.8.909. http://dx.doi.org/10.1001/archinte.1997.00440290095010 
Jackson, J. L., Gibbons, R, Meyer, G. \& Inouye, L. (1997). The effect of treating herpes zoster with oral acyclovir in preventing postherpetic neuralgia. A meta-analysis. Arch Intern Med, 157, 909-912. http://dx.doi.org /10.1001/archinte.157.8.909. http://dx.doi.org/10.1001/archinte.1997.00440290095010

Johnson, R. W. \& Dworkin, R. H. (2003). Treatment of herpes zoster and postherpetic neuralgia. BMJ, 326, 748-750. http://dx.doi.org/10.1136/bmj.326.7392.748

Jung, B. F. , Johnson, R. W. , Griffin, D. R. \& Dworkin, R. H. (2004). Risk factors for postherpetic neuralgia in patients with herpes zoster. Neurology, 62, 1545-1551

Kimberlin, D. W. \& Whitley, R. J. (2007). Varicella-Zoster vaccine for the prevention of herpes zoster. $N$ Eng $J$ Med, 356, 1338-1343. http://dx.doi.org/10.1056/NEJMct066061

Kuraishi, Y., Takasaki, I., Nojima, H., Shiraki, K. \& Takahata, H. (2004). Effects of the suppression of acute herpetic pain by gabapentin and amitriptyline on the incidence of delayed postherpetic pain in mice. Life Sci, 74, 2619-2626. http://dx.doi.org/10.1016/j.lfs.2004.01.005

Lang, P. O. \& Michel, J. P. (2011). Herpes zoster vaccine: What are the potential benefits for the ageing and older adults? Eur Geriatr Med, 2, 134-139. http://dx.doi.org/10.1016/j.eurger.2011.06.001

Lang, P. O., Belmin, J. \& Michel, J. P. (2009). Herpes zoster in old adults. Press Med, 38, 571-583. http://dx.doi.org/10.1016/j.lpm.2008.05.019

Lang, P. O., Herrmann, F. \& Michel, J. P. (2007) .Varicella-zoster vaccine. N Eng J Med, 357:89

Lang, P. O., Pautex, S., Belmin, J. \& Michel, J. P. (2010). Herpes zoster-related pain in aged individuals: How to manage it safely. Eur Geriatric Med, 1, 273-275. http://dx.doi.org/10.1016/j.eurger.2010.07.017

Levin, M. J. \& Hayward, A. R. (1996) .The varicella vaccine. Prevention of herpes zoster. Infect Dis Clin North Am, 10, 657-675. http://dx.doi.org/10.1016/S0891-5520(05)70319-6

Li. Q., Chen, N., Yang, J., Zhou, M., Zhang, Q. \& He, L. (2009). Antiviral treatment for preventing postherpetic neuralgia. Cochrane Database Syst Rev CD006866.

Lu, P., Euler, G. L., Jumaan, A. O. \& Harpaz, R. (2009). Herpes zoster vaccination among adults aged 60 years or older in the United States, 2007: Uptake of the first new vaccine to target seniors. Vaccine, 27, 882-887. http://dx.doi.org/10.1016/j.vaccine.2008.11.077

McGuire, T., Wells, K. B., Bruce, M. L., Miranda, J., Scheffer, R., Durham, M., Ford, E. \& Lewis, L. (2002). Burden of illness. Ment Health Serv Res, 4, 179-185. http://dx.doi.org/10.1023/A:1020956313890

Opselten, W. M .J., de Wit, N. J., van Wijck, A. J., Stalman, W. A. \& van Essen, G. A. (2002). Herpes zoster and post-herpetic neuralgia: incidence and risk indicators using in general practice research database. Fam Pract, 19, 471-475. http://dx.doi.org/10.1093/fampra/19.5.471

Oxman, M. N. \& Levin, M. J. (2008). Shingles Prevention Study Group Vaccination against Herpes Zoster \& Postherpetic Neuralgia. J Infect Dis, 197 Suppl 2, S228-236. http://dx.doi.org/10.1086/522159

Oxman, M. N., Levin, M. J. \& Johnson, G. R. (2005) A vaccine to prevent herpes zoster and postherpetic neuralgia in older adults. $N$ Eng $J$ Med, 352, 2271-2284. http://dx.doi.org/10.1056/NEJMoa051016

Scott, F. T., Johnson, R. W., Leedham-Green, M., Davies, E., Edmunds, W. J. \& Breuer, J. (2006). The burden of Herpes Zoster: a prospective population based study. Vaccine, 24, 1308-1314. http://dx.doi.org/10.1016/j.vacc ine.2005.09.026

Stein, A. N., Britt, H., Harrison, C., Conway, E. L., Cunningham, A. \& MacIntyre, C. R. (2009). Herpes zoster burden of illness and health care resource utilization in the Australian population aged 50 years and older. Vaccine, 22;27, 520-9

Thomas, S. L. \& Hall, A. J. (2004). What does epidemiology tell us about risk factors for herpes zoster. Lancet Infect Dis, 4, 26-33. http://dx.doi.org/10.1016/S1473-3099(03)00857-0

Tyring, S., Barbarash, R. A., Nahlik, J. E., Cunningham, A., Marley, J. \& Heng, M. (1995). Famciclovir for the treatment of acute herpes zoster: effects on acute disease and postherpetic neuralgia. A randomized, double-blind, placebo-controlled trial. Collaborative Famciclovir Herpes Zoster Study Group. Ann Intern Med, 123, 89-96. http://dx.doi.org/10.1016/j.vaccine.2008.11.012

van Wijck, A. J., Opstelten ,W., Moons, K. G., van Essen, G. A., Stolker, R. J., Kalkman, C. J. \& Verheij, T. J. (2006). The PINE study of epidural steroids and local anaesthetics to prevent postherpetic neuralgia: a randomized controlled trial. Lancet, 367, 219-224. http://dx.doi.org/10.1016/S0140-6736(06)68032-X 
Wareham, D. W. \& Breuer, J. (2007). Herpes zoster. BMJ, 334, 1211-1215. http://dx.doi.org/10.1136/bmj.39206. 571042.AE

Whitley, R. J., Weiss, H., Gnann, J. W. Jr., Tyring, S., Mertz, G. J. \& Pappas, P. G. (1996). Acyclovir with and without prednisone for the treatment of herpes zoster. A randomized, placebo-controlled trial. The National Institute of Allergy and Infectious Diseases Collaborative Antiviral Study Group. Ann Intern Med, 125, 376-383.

Wood, M. J, Kay, R., Dworkin, R. H., Soong, S. J. \& Whitley, R. J. (1996). Oral acyclovir therapy accelerates pain resolution in patients with herpes zoster: a meta-analysis of placebo-controlled trials. Clin Infect Dis, 22, 341-347. http://dx.doi.org/10.1093/clinids/22.2.341

Wood, M. J. (1994). Current experience with antiviral therapy for acute herpes zoster. Ann Neurol, 35, S65-68. http://dx.doi.org/10.1002/ana.410350719

Table 1. Burden of Herpes zoster (HZ) disease from an observational study conducted in France over a 1-year-period. Quality-of-life was assessed from a self-questionnaire in patients who presented with acute $\mathrm{HZ}$ or post-herpetic neuralgia at the office of practices of general practitioners or dermatologist (from Chidiac et al)

\begin{tabular}{|c|c|c|}
\hline \multirow{2}{*}{$\begin{array}{l}\text { Symptom or complaint } \\
\text { HZ responsible for pain }\end{array}$} & \multicolumn{2}{|c|}{$\begin{array}{c}\text { Total }=7,595 \\
\mathrm{n}(\%)\end{array}$} \\
\hline & 6,759 & $(89)$ \\
\hline Pain characterized by burning sensations & 4,557 & $(60)$ \\
\hline Permanent pain & 3,190 & $(42)$ \\
\hline Severe to very severe pain & 3,417 & $(45)$ \\
\hline Marked decrease in physical activities & 2,734 & $(36)$ \\
\hline Marked decrease in walking time & 2,202 & $(29)$ \\
\hline Marked impact of social life & 1,519 & $(20)$ \\
\hline Impact on sleep & 4,481 & $(59)$ \\
\hline Anxiety & 2,278 & $(30)$ \\
\hline
\end{tabular}


Table 2. Treatment of acute herpes zoster in immunocompetent old adults, and recommended dose adjustment with creatinine clearance (Cockcroft and Gault creatinine clearance)

\begin{tabular}{|c|c|c|c|c|c|}
\hline \multirow{2}{*}{$\begin{array}{l}\text { Antiviral } \\
\text { drugs }\end{array}$} & \multicolumn{2}{|c|}{ Dose/frequency } & \multirow{2}{*}{$\begin{array}{c}\text { Treatment } \\
\text { duration }\end{array}$} & \multirow[b]{2}{*}{ Efficacy } & \multirow[b]{2}{*}{ Notes } \\
\hline & $\begin{array}{l}\text { Dose in } \\
m g / \text { day }\end{array}$ & $\begin{array}{c}\text { Adjustment with } \\
\text { Creatinine clearance } \\
\text { a }\end{array}$ & & & \\
\hline \multirow[t]{6}{*}{ Acyclovir } & \multirow{6}{*}{$\begin{array}{c}800 \mathrm{mg} \\
5 \text { times daily }\end{array}$} & $>25 \mathrm{~mL} / \mathrm{min}$ & \multirow{6}{*}{ 7-10 days } & \multirow{6}{*}{$\begin{array}{c}\text { Reduces acute pain and } \\
\text { development of PHN }\end{array}$} & \multirow{6}{*}{$\begin{array}{c}\text { Most effective } \\
\text { if started } \\
\text { within } 72 \\
\text { hours of onset } \\
\text { of rash }\end{array}$} \\
\hline & & $4000 \mathrm{mg}$ daily & & & \\
\hline & & $10-25 \mathrm{~mL} / \mathrm{min}$ & & & \\
\hline & & 2400mg daily & & & \\
\hline & & $<10 \mathrm{~mL} / \mathrm{min}$ & & & \\
\hline & & $1600 \mathrm{mg}$ daily & & & \\
\hline Valacyclovir & \multirow{6}{*}{$\begin{array}{c}1000 \mathrm{mg} \\
3 \text { times daily }\end{array}$} & $>25 \mathrm{~mL} / \mathrm{min}$ & \multirow{6}{*}{7 days } & \multirow{6}{*}{$\begin{array}{l}\text { Reduces acute pain and } \\
\text { development of PHN }\end{array}$} & \multirow{6}{*}{$\begin{array}{l}\text { Most effective } \\
\text { if started } \\
\text { within } 72 \\
\text { hours of onset } \\
\text { of rash }\end{array}$} \\
\hline & & $3000 \mathrm{mg}$ daily & & & \\
\hline & & $10-25 \mathrm{~mL} / \mathrm{min}$ & & & \\
\hline & & $2000 \mathrm{mg}$ daily & & & \\
\hline & & $<10 \mathrm{~mL} / \min$ & & & \\
\hline & & $1000 \mathrm{mg}$ daily & & & \\
\hline \multirow[t]{6}{*}{ Famciclovir } & \multirow{6}{*}{$\begin{array}{c}750 \mathrm{mg} \text { daily } \\
\text { or } \\
250 \mathrm{mg} \\
3 \text { times daily }\end{array}$} & $>25 \mathrm{~mL} / \mathrm{min}$ & \multirow{6}{*}{7 days } & \multirow{6}{*}{$\begin{array}{c}\text { Reduces acute pain and } \\
\text { development of PHN }\end{array}$} & \multirow{6}{*}{$\begin{array}{c}\text { Most effective } \\
\text { if started } \\
\text { within } 72 \\
\text { hours of onset } \\
\text { of rash }\end{array}$} \\
\hline & & $750 \mathrm{mg}$ daily & & & \\
\hline & & $10-25 \mathrm{~mL} / \mathrm{min}$ & & & \\
\hline & & 500mg daily & & & \\
\hline & & $<10 \mathrm{~mL} / \mathrm{min}$ & & & \\
\hline & & 250mg daily & & & \\
\hline
\end{tabular}

${ }^{a}$ Creatinine clearance in $\mathrm{mL} / \mathrm{min}$ : ((140-age) $\mathrm{x}$ weight $) \mathrm{x} \mathrm{K} /$ creatinine, with: $\mathrm{K}=1.24$ for males and 1.04 in females; age in years; weight in $\mathrm{kg}$ and plasma creatinine in $\mu \mathrm{mol} / \mathrm{L}$. 